\title{
The milk debate, conflicts of interest, and our Christmas appeal
}

\author{
Fiona Godlee editor in chief, The BMJ
}

Last week I suggested that nutrition was more important in medicine than some of us had thought (doi:10.1136/bmj.g7255). This week we publish letters in response to our most widely read paper of the year so far, on milk consumption and mortality (doi:10.1136/bmj.g6993, doi:10.1136/bmj.g6995, doi:10.1136/ bmj.g7000, doi:10.1136/bmj.g7006, doi:10.1136/bmj.g7012). The paper, by Michaelsson and colleagues (BMJ 2014;349:g6015, doi:10.1136/bmj.g6015), reported analyses from two large prospective Swedish cohorts and raised the possibility that milk could increase the risk of hip fracture in women and cardiovascular and overall mortality in both sexes. When researchers conclude that a ubiquitous and much championed component of the western diet may be associated with ill effects, it's not surprising that people sit up and listen, nor that the debate on thebmj.com has been lively and varied. Our respondents challenge the authors for not taking into account confounding by vitamin D status or the effects of pasteurisation and modern milk production. They question whether fermented and unfermented milk products are really so different and ask what is behind the apparent sex difference in fracture risk.

The authors give a measured and comprehensive response (doi:10.1136/bmj.g7023). Although in their paper they proposed a mechanism to explain their findings (involving lactose metabolism and genetic lactase persistence), they also advised caution in drawing conclusions from their data. Given that milk consumption is increasing worldwide and that most dietary recommendations rely on observational evidence, vigorous debate and a degree of scepticism about current guidance seem a reasonable approach.
Elsewhere we announce our new more stringent policy on financial conflicts of interest among authors of our educational articles (doi:10.1136/bmj.g7197). This has been several years in the making. Now, after much discussion among the journal's editors and external advisers, we have decided that we will no longer commission editorials, clinical reviews, and practice articles from authors with financial ties to industry. We will phase the policy in, beginning with editorials, clinical reviews, and most practice series. We plan to extend it to the rest of our education section-state of the art reviews and diagnostic and therapeutic series_-by the end of 2016.

Despite our own and other people's concerns that we would find this impossible to implement, our initial experience has been positive. We are grateful to our authors for engaging with the process, and the cluster of education articles published in the 6 December print issue is a good start, with authors of two of the three articles having no links to commercial companies (doi:10.1136/bmj.g4531, doi:10.1136/bmj.g6560, doi:10.1136/ bmj.g6722). As we say in our editorial, we are willing to miss out on articles on a few topics in exchange for publishing more articles from authors without financial ties to industry. We will report back on how we get on, and we welcome your views.

Finally, this week we launch our Christmas appeal (doi:10.1136/ bmj.g7402). We have chosen to support Médecins Sans Frontières, as we did six years ago, having again been struck by its effectiveness, neutrality, independence, and collaborative ethos. Please give generously, as you have in the past. You can donate online at msf.org.uk/thebmj.

Cite this as: BMJ 2014;349:97447

๑ BMJ Publishing Group Ltd 2014 